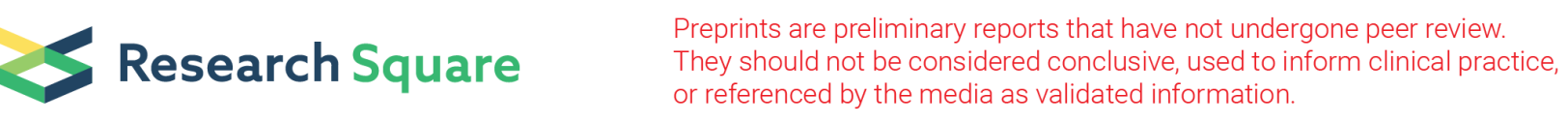

\title{
Can we scale up a comprehensive school-based eye health programme in Zambia?
}

\section{Ai Chee Yong}

Queen's University Belfast, Northern Ireland

\section{Anne Buglass}

Vision Aid Overseas

\section{Godfrey Mwelwa}

Vision Aid Overseas

Ibrahim Abdallah

Vision Aid Overseas

Ving Fai Chan ( $\nabla$ v.chan@qub.ac.uk)

Queen's University Belfast, Northern Ireland

\section{Research Article}

Keywords: school-based eye health programme, scalability assessment, uncorrected refractive error, vision impairment, childhood blindness

Posted Date: August 31st, 2021

DOl: https://doi.org/10.21203/rs.3.rs-658764/v2

License: (c) (i) This work is licensed under a Creative Commons Attribution 4.0 International License. Read Full License 


\section{Abstract \\ Background}

Globally, 19 million children have preventable vision impairment simply because refractive and eye health services are inaccessible to most of them. In Zambia, 50,000 school children need spectacle provision. The School-based Eye Health Programme (SEHP) has been identified worldwide as a proven strategy to address childhood blindness. Given the great benefits of it, the Zambian government intends to scale up the programme. This scalability assessment aims to identify and evaluate the essential components of an effective SEHP, determine roles, assess existing capacities within user organisations, identify environmental facilitating and inhibiting factors, and estimate the minimum resources necessary for the scaling up and their proposed scale-up strategies.

\section{Methods}

Five elements (innovation, user organisation, resource team, environment, and strategies for horizontal and vertical scaling-up) were assessed guided by the ExpandNet-WHO Nine Steps for Developing a Scaling-Up Strategy. Literature reviews and stakeholders' interviews were conducted to collect data for this assessment. Subsequently, twenty questions in the Worksheets for Developing a Scaling-up Strategy were used to systematically reporting the assessment outcome.

\section{Results}

Additional components of SEHP incorporated in Zambia's model enhanced the innovation's credibility and relevance. The resource team was relatively competent in the pilot, and the same team will be employed during the scaling-up. Political instability, the lack of supply chain, and unstable financial supports were identified as inhibiting factors. The objectives of SEHP were aligned with the National Eye Health Strategic Plan 2017-2021 that support the institutionalisation of the SEHP into the existing School Health and Nutrition Programme. For the pace of expansion, replicating SEHP to another district rather than a province will be more realistic.

\section{Conclusion}

Scaling up a comprehensive SEHP in Zambia is feasible, provided if sufficient funding is available. Additionally, the pace must be adapted to the local context to ensure that every component within the SEHP is intact.

\section{Background}


Globally, 19 million children have vision impairment (VI) mainly due to uncorrected refractive error (URE), congenital cataract and glaucoma, corneal opacities, trachoma, and retinal disorders.[1] URE is identified as the leading cause of $\mathrm{VI}$, affecting 12.8 million children simply because they do not have access to refractive services and spectacle corrections. Unfortunately, approximately $90 \%$ of the heavy burden falls in low- and middle-income countries, which further stretches the health systems that were already underresourced.[2] Because of poor vision, children were more likely to have a limited academic achievement that may affect their future career opportunities and livelihood [3-7] and experienced psychosocial effects such as depression, stress, anxiety disorders which may negatively impact their quality of life.[810]

While there is no published population-based information on the burden of childhood VI in Zambia, anecdotal evidence shows that an estimated 50,000 Zambian children had an unmet need for refractive services in 2020.[11]To address this burden,[12] the Ministries of Health and General Education initiated a pilot comprehensive School-based Eye Health Programme (SEHP) collaboratively with Vision Aid Overseas, an eye care non-governmental organisation (NGO) focusing on reducing the burden of URE in low-resource settings. The pilot consisted of eye health screening, provision of free spectacle correction and prescription of eye ointment to treat common eye ailments such as allergic conjunctivitis, and dissemination of eye health knowledge to the community.

SEHP has been adopted as a successful platform to deliver interventions such as disseminating nutrition and health knowledge to parents to avoid Vitamin A deficiency blindness, accelerating vaccination uptake to avoid measles-related eye diseases, and promoting SAFE strategy to prevent trachoma (surgery for trichiasis, antibiotics, face cleanliness and environmental improvement). These innovative interventions reduced the number of blind children by $24 \%$ in the last 30 years, despite massive population growth.[13]

Given the great benefits of SEHP,[14] the Zambian Ministries of Health and General Education intend to scale up the SEHP to benefit more children. However, the scale-up must be done gradually and systematically to ensure the programme's effectiveness and sustainability, besides providing children with quality eye health services. Therefore, this scalability assessment aims to identify and evaluate the essential components and operations of an effective SEHP, determine roles, assess existing capacities within user organisations, identify environmental facilitating and inhibiting factors for scaling-up, estimate the minimum resources necessary for scaling up, and finally to propose strategies.

\section{Methods}

The ExpandNet-WHO Nine Steps guided the assessment for developing a scaling-up strategy for SEHP in Zambia.[15] It supported a systematic approach for institutionalising and expanding the comprehensive SEHP based on experience derived from the pilot project. We assessed all the elements, including the innovation, user organisation, resource team, environment, and vertical and horizontal scaling-up strategies. (Table 1) We also identified these elements' strengths and weaknesses, facilitating and inhibiting factors. Based on the findings, we made recommendations and proposed potential strategies 
for scaling up. Subsequently, the ExpandNet-WHO Checklist for assessing the potential scalability of pilot projects or other programmatic research[16] was completed to determine how much information or action is needed to facilitate a sustainable scaling up. The checklist was organised into 12 questions based on the elements outlined in ExpandNet-WHO Nine Steps for Developing a Scaling Up Strategy.

Table 1

The elements for scaling up of a comprehensive School-based Eye Health Programme

\section{Elements for scaling up}

Element The innovation

1

The package of interventions or other

new practices being scaled up.

\section{Element User organisation/s}

2

The institution or organisations

intended to adopt and implement the

innovation on a large scale.

\section{Element Resource team}

3

The individuals and organisations

promoting scale up of the innovation.

\section{Descriptions}

Comprehensive School-based Eye Health

Programme (SEHP).

Zambian Ministry of General Education (MOGE) and Ministry of Health (MOH), and Vision Aid Overseas (VAO).

\begin{abstract}
VAO country team, MOH's and MoGE's representatives, Provincial Health Director, Provincial Education Officer, District Health Officer, District Education Board Secretary, School Heads/ Head Teachers,

Schoolteachers, Ophthalmic Nurses, Ophthalmic Clinical Officers, Ophthalmologists, Optometry Technologists, focal person for mobile eye health clinics.
\end{abstract}

\section{Element Environment}

4

The conditions and institutions which are external to the user organisation but affect the success of scaling up.

Element Scaling-up strategies 5

The scaling-up strategy is the plan for promoting, expanding and institutionalising the innovation. Development of an effective scaling up strategy assesses the elements of scaling up and the actions needed to improve them and then examines the strategic choices for each of the four types of scaling up.
Macro- and micro-environment, which considers the cultural views and receptivity of the local community towards the SEHP, and the political supports to incorporate child eye health into the national health policies.

Types of scaling up:

i. Horizontal scaling up refers to the expansion or replication of the pilot to different geographical areas or serving different populations.

ii. Vertical scaling up refers to institutionalising the programme embedded in the policies, organisational structures, and operational guidelines.

An experienced global health optometrist (ACY) conducted the scalability assessment from September to December 2020, employing a mixed-methods approach. ACY reviewed the literature on proven strategies in reducing the burden of childhood VI, SEHP implemented in both high-income and low- and middleincome countries, and the effectiveness of a comprehensive SEHP in improving health and educational achievement. ACY also reviewed the Standard Guideline for a Comprehensive SEHP developed by the 
International Agency for the Prevention of Blindness,[12] project reports from Vision Aid Overseas, the Zambian National Health Strategic Plan 2017-2021,[17] National Eye Health Strategic Plan 2017-2021, [18] and the National School Screening Programme Protocol 2020.

Due to the COVID-19 pandemic and therefore, field trip to Zambia was restricted, ACY subsequently interviewed six key informants from the Ministry of Health (MOH), Ministry of General Education (MoGE) and Vision Aid Overseas (VAO). These key informants are the National Eye Care Coordinator, Kafue District Education Planner, VAO Zambia Country Director and Project Coordinator, VAO Programme Director and Deputy Programme Director. Questionnaires were developed to collect information on facilitating and inhibiting factors and areas that needed to be strengthened to ensure an effective scaling up.

Responses from the questionnaires and outcome from the interviews were analysed based on the Worksheets for Developing a Scaling-up Strategy.[19] This worksheet provided a detailed set of questions for the strategic planning process. The 20 questions in this worksheet were used as a guide to developing the assessment report.

\section{Results}

\section{Element 1 - An assessment of the components on a comprehensive School-based Eye Health Programme}

Many school vision screening projects conducted in Zambia were mainly event-based (routine practice), lacking consistency and scale. NGOs heavily drove the project, and as a result, the establishment of local ownerships and leaderships were limited. Table 2 demonstrated the advantages of the Zambia model over other routine practices using the Likert scale. A few prominent components in the Zambian model were the inclusion of local community engagement, programme monitoring and evaluation, and building a vision for up-scaling the programme. 
Table 2

Comparison of components between comprehensive School-based Eye Health Programme and routine practices

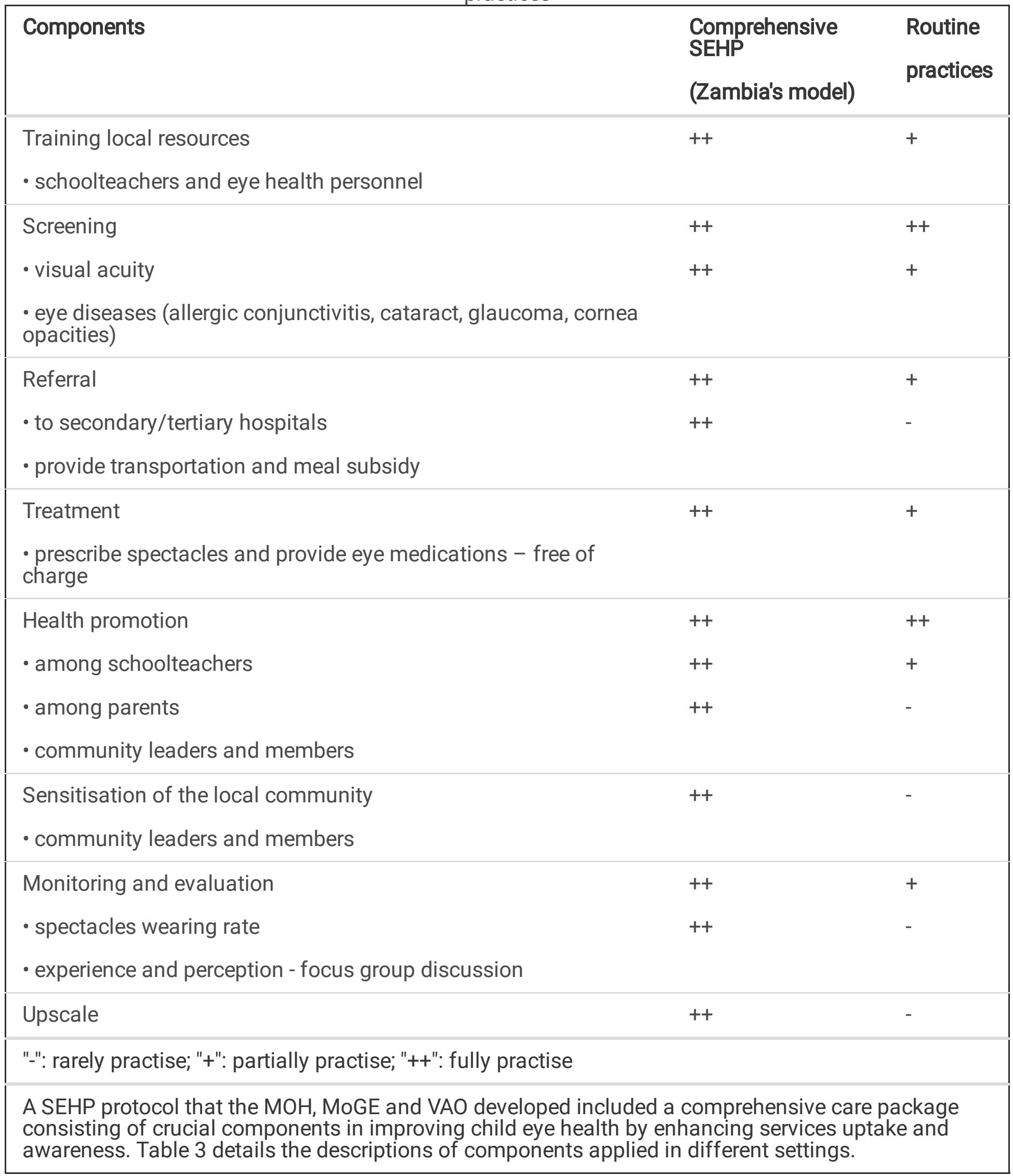


Table 3

Description of components of the comprehensive School-based Eye Health Programme

\begin{tabular}{|c|c|c|}
\hline Components & Settings & Descriptions \\
\hline $\begin{array}{l}\text { Training of } \\
\text { schoolteachers }\end{array}$ & $\begin{array}{l}\text { Workshops } \\
\text { (conducted by } \\
\text { OCOs, ONs and } \\
\text { OTs) }\end{array}$ & $\begin{array}{l}\text { - A two-day training (both theory and practical) will be } \\
\text { conducted, covering topics such as common eye diseases in } \\
\text { children, refractive errors, general eye health, hygiene and } \\
\text { face washing, eye screening and recording, and identifying } \\
\text { children with poor vision in the classroom, child protection } \\
\text { and safeguarding. }\end{array}$ \\
\hline \multirow[t]{2}{*}{ Screening } & Schools & • Visual acuity measurement. \\
\hline & $\begin{array}{l}\text { (conducted by } \\
\text { schoolteachers) }\end{array}$ & $\begin{array}{l}\text { - External eye observation (cornea, eyelid, pupil, conjunctiva, } \\
\text { sclera). }\end{array}$ \\
\hline \multirow[t]{4}{*}{ Referral } & \multirow{4}{*}{$\begin{array}{l}\text { MEHCs } \\
\text { (conducted by } \\
\text { OCOs, ONs and } \\
\text { OTs) }\end{array}$} & $\begin{array}{l}\text { - Examinations of referred children who failed screening in } \\
\text { schools, which included: }\end{array}$ \\
\hline & & $\begin{array}{l}\neg \text { perform cycloplegic refraction and prescribe spectacles if } \\
\text { significant refractive error was observed. }\end{array}$ \\
\hline & & $\begin{array}{l}\neg \text { perform a detailed eye examination and prescribe eye } \\
\text { medications when necessary. }\end{array}$ \\
\hline & & $\neg$ refer complicated eye conditions to hospitals. \\
\hline Treatment & $\begin{array}{l}\text { Secondary/ } \\
\text { Tertiary hospitals } \\
\text { (examined by } \\
\text { ophthalmologists, } \\
\text { optometrists/OTs) }\end{array}$ & $\begin{array}{l}\text { - Manage complex eye diseases which may require surgical } \\
\text { interventions, e.g. cataract, glaucoma, or more complex } \\
\text { refraction. }\end{array}$ \\
\hline \multirow[t]{2}{*}{$\begin{array}{l}\text { Service } \\
\text { delivery }\end{array}$} & \multirow[t]{2}{*}{ Schools, MEHCs } & $\begin{array}{l}\text { - Prescribe spectacles (ready-to-clip spectacles) and eye } \\
\text { medications onsite or deliver to schools (custom-made } \\
\text { spectacles). }\end{array}$ \\
\hline & & $\begin{array}{l}\text { - Provide per diems to referred children's families to cover } \\
\text { transportations expenses and meals. }\end{array}$ \\
\hline \multirow[t]{4}{*}{$\begin{array}{l}\text { Monitoring } \\
\text { and evaluation }\end{array}$} & \multirow{2}{*}{$\begin{array}{l}\text { (i) Schools, } \\
\text { MEHCs, Hospitals } \\
\text { (by teachers, } \\
\text { OCOs, ONs, } \\
\text { ophthalmologists) }\end{array}$} & $\begin{array}{l}\text { - Schools, MEHCs and hospitals work together to have a } \\
\text { proper data monitoring system to follow up those referred } \\
\text { children who attended the MEHCs/hospitals. }\end{array}$ \\
\hline & & - Evaluation of spectacles wearing rate. \\
\hline & (ii) Schools & $\begin{array}{l}\text { - Focus group discussion on perceptions towards SEHP and } \\
\text { interventions such as spectacles and eye medications. }\end{array}$ \\
\hline & $\begin{array}{l}\text { (by teachers, } \\
\text { MOH, MoGE) }\end{array}$ & \\
\hline
\end{tabular}




\begin{tabular}{|c|c|c|}
\hline Components & Settings & Descriptions \\
\hline $\begin{array}{l}\text { Health } \\
\text { promotion and } \\
\text { education }\end{array}$ & $\begin{array}{l}\text { Schools, } \\
\text { communities } \\
\text { (conducted by } \\
\text { schoolteachers) }\end{array}$ & $\begin{array}{l}\text { - Workshops (Parent-Teacher Association platform) for } \\
\text { parents and local leaders which cover topics such as the } \\
\text { importance and stigma of spectacles wear, eye health } \\
\text { hygiene, face washing (to prevent trachoma, eye infections), } \\
\text { proper eye health nutrition (Vitamin A), and promote health-- } \\
\text { seeking behaviour. }\end{array}$ \\
\hline $\begin{array}{l}\text { Engagement } \\
\text { with local }\end{array}$ & $\begin{array}{l}\text { Schools, } \\
\text { communities }\end{array}$ & $\begin{array}{l}\text { - Visit schools and inform School Heads about the } \\
\text { programme and seek support. }\end{array}$ \\
\hline communities & $\begin{array}{l}\text { (conducted by } \\
\text { VAO, } \\
\text { accompanied by } \\
\text { District Health } \\
\text { Officer and } \\
\text { District Education } \\
\text { Board Secretary) }\end{array}$ & $\begin{array}{l}\text { - Visit communities and meet local leaders to inform them } \\
\text { about the programme and seek support. }\end{array}$ \\
\hline \multicolumn{3}{|c|}{$\begin{array}{l}\text { OCOs: ophthalmic clinical officers; ONs: ophthalmic nurses; OTs: optometry technologists; MEHCs: } \\
\text { mobile eye health clinics }\end{array}$} \\
\hline \multicolumn{3}{|c|}{$\begin{array}{l}\text { The comprehensive SEHP piloted in the Kafue district has demonstrated remarkable achievement in } \\
\text { the Zambian context (from } 17 \text { th June } 2019 \text { to } 17 \text { th December } 2019 \text { ). The pilot screened } 18,713 \text { Grade } \\
1 \text { to } 9 \text { children (coverage of } 43.15 \% \text { ) from the } 73 \text { schools and identified } 3,817 \text { children with eye } \\
\text { problems (dispensed } 600 \text { pair of spectacles, referred } 68 \text { children to a tertiary hospital for further care, } \\
\text { and prescribed more than } 3,000 \text { bottles of eye drops). The project also trained } 154 \text { schoolteachers to } \\
\text { detect common eye problems and make referrals, engaged with three local optometry technologists } \\
\text { and one local ophthalmologist, and utilised three ophthalmic clinical officers (OCOs) and ophthalmic } \\
\text { nurses (ONs) to conduct the mobile eye health clinics (MEHCs) in } 6 \text { zones. }\end{array}$} \\
\hline \multicolumn{3}{|c|}{$\begin{array}{l}\text { A review of the available policies shows that the SEHP aligns with the National Health Plan } 2017- \\
2021 \text {, the National Eye Health Strategic Plan } 2017-2021 \text { and VAO's mission. In the pilot, all the } \\
\text { referred children attended the MEHCS ( } n=2,818 \text {, no loss-to-follow-up), and an additional } 3,140 \\
\text { community children turned up in MEHCs seeking eye examinations. Reflecting upon this, we assume } \\
\text { that the local communities' response seems promising, and they showed support to the programme. }\end{array}$} \\
\hline
\end{tabular}

\section{Element 2 - An assessment of user organisations (Vision Aid Overseas, the Zambian Ministry of Health, and Ministry of General Education)}

All three organisations (VAO, MOH and MoGE) were involved fully in the Kafue district's pilot project. Our assessment showed that $\mathrm{MOH}$ could effectively train schoolteachers as screeners, while local resources such as OCOs, ONs and Optometry Technologists (OTs) can be mobilised to districts where resources are limited. Four local institutions can train eye health resources: Levy Mwanawasa Medical University, University of Zambia, Kitwe Teaching Hospital, and Ndola Teaching Hospital.

In terms of leadership, VAO took the lead on supervision and coordination in the pilot project while the National Eye Care Coordinator ( $\mathrm{MOH}$ ) and District Education Board Secretary (MoGE) closely supported VAO. The assessment suggested that the leading team will need to be further equipped with managerial skill, capacity for advocating and researching, and monitoring and evaluation skills. 
Due to the lack of reliable supply chains in Zambia for affordable quality spectacles, VAO provided children with spectacles and eye medications during the pilot project. Physical facilities were readily available where schools were used as screening venues and MEHCs as treatment points.

The most significant inhibiting factor is that there is no policy and legal framework that included SEHP, despite its effectiveness in targeting child eye health disorders and other cross-cutting issues such as Vitamin A deficiency. Furthermore, VAO, an NGO that heavily relies on donors and grants, is uncertain of the available funding.

\section{Element 3 - An assessment of the environment for scaling} up

\section{Micro-environment - factors such as interaction among people and organisations and logistic accessibility}

The pilot revealed that the schools and communities showed no objections to government initiatives as school heads and community leaders felt respected when informed about the SEHP plan. Schoolteachers and health personnel were dedicated to participating in screening and management programmes for children because the organising committee created an enabling environment to support teachers with training, small incentives and meals, and transportations reimbursement. Furthermore, MEHCs that visit schools addressed the geographical barriers by bringing the services closer to the communities.

Macro-environment - factors that may have a greater impact on the scale-up effort, such as at the political, economic and societal level

VAO has a well-established partnership with the Zambian MOH and MoGE. The implementation and advocacy of comprehensive SEHP may be affected if there is a change in existing government administration. However, the political factor is beyond the team's control. According to the National Eye Care Coordinator and the District Health Officer, the time it takes for the government to include SEHP into the existing School Health and Nutrition Programme (SHNP) was uncertain. Many factors may influence the outcome, especially the political will and budget availability. Other health initiatives may also compete with SEHP.

The supply chain has yet to be developed and hence, inadequate in Zambia. Currently, there are only two suppliers of lenses and frames. VAO is responsible to source for frames, lenses and medications to support the management of referred children. VAO has applied to the Zambia Revenue Authority for Public Benefit Organisation status and envisaged that tax exemption would be granted to minimise the costs.

\section{Element 4 - An assessment of the resource team for scaling up}


The scaling-up of the SEHP requires a team working top at the national level and down to province and district level, and finally to schools and communities. The leading team which developed and tested the pilot project will be readily available during the scaling-up. The assessment found that they possess capacities such as:

- in-depth understanding of the user organisation's capacities and limitations;

- capacity to train members of the user organisation;

- effective and motivated leaders with a unifying vision who have authority and credibility with the user organisation;

- understanding of the political, social and cultural environments within which scaling-up takes place;

- ability to advocate in favour of the innovation with policy-makers, government officials and programme managers;

- skills and experience with scaling-up;

- availability to provide support over a multi-year period.

Nevertheless, continuous effort to strengthen the capacities within the leading team is needed.

The Kafue pilot project has built the competency within the user organisations to sensitise the local community, train many schoolteachers, and coordinate logistics. Besides, information such as the prevalence of children needing spectacles or eye drops will help effective future planning and consumable procurement. Given the size of the resource team, there is a need to recruit several project officers to oversee the project at the simultaneous implementations in multiple districts. Senior Medical Superintendents of eye clinics/hospitals (SMS) were identified as additional resources to support the MEHCs when the SEHP expands to a new district.

\section{Element 5 - Determining the role of policy/legal/political scaling up (vertical scaling up)}

The National Health Strategic Plan 2017-2021 (NHSP) has included eye health as a non-communicable disease that needed to be prioritised.[17] The 3rd National Eye Health Strategic Plan (NEHSP) aims to achieve eye health coverage across the country to at least $90 \%$ by 2021.[20] Furthermore, SEHP is likely to cover the maximum number of children and be a practical approach to achieving this goal.

Despite the strategy of capacity building among schoolteachers and community leaders to detect common eye diseases as mentioned in NHSP 2017-2021, a description of the comprehensive SEHP was not highlighted nor emphasised. SEHP has excellent potential to contribute to a few critical objectives stated in NEHSP 2017-2021 (shown in Table 4). Therefore, a policy change is considerably needed. 
Objectives and strategies in the 3rd National Eye Health Strategic Plan [18]

$\begin{array}{ll}\text { Objectives } \quad \text { Strategies } & \text { Will the comprehensive } \\ & \text { School-based Eye Health } \\ & \text { Programme contribute to this? }\end{array}$

4.0 Eye health $\quad$ 4.1.1 To promote good eye health and prevention $\sqrt{ }$ system of eye diseases by $100 \%$

strengthening

4.2.1.2 To reduce the prevalence of active trachoma by $50 \%$ in children $1-9$ years old 4.2.3.1 To provide refractive services in more $\quad \sqrt{ }$ than $50 \%$ of the districts in the country

5.0 Integration with the wider health system
5.1.1 To ensure non-eye health workers have a better understanding of eye health conditions and can take appropriate actions

$\checkmark$

$\sqrt{ }$

$\sqrt{ }$

5.2.1 To increase the number of eye health referrals that receive treatment in eye health facilities by $20 \%$

5.3.1 Children with eye conditions are identified $\quad \sqrt{ }$ through a school vision screening programme

6.0 Equity of access to eye health services

7.0 Strong and effective partnerships

8.0 Research and evidence

9.0 Monitoring and evaluation

\subsubsection{People in rural areas access basic eye} health services in district hospitals
7.1 To enhance the partnership between government, private institutions and co-operating partners in the eye health sector

8.1 To generate evidence-based data for eye health specific to the Zambian context

9.1 To strengthen the monitoring and evaluation in the delivery of the NEHSP 2017-2021

The integration of SEHP into the SHNP would be critical if the government formally adopted the programme. One of the strategies to achieving this is through advocacy to the government (i.e. vertical upscaling). The government's full support is essential in ensuring the programme's sustainability, referring to resources allocation such as human resources (eye health personnel in public hospitals) and funding (national health budget).

There are a few valid reasons that the inclusion of child eye health into SHNP will be an effective approach to address the burden of childhood blindness: (i) SHNP is already established in all the schools in Zambia; (ii) besides nutrition and other health-related issues, eye health is vital in children's development; (iii) the integration of the eye health into SHNP was shown to be more cost-effective as compared to the individual programme.[21] 
VAO has committed initial seed funding based on the available grants from international donors. Longerterm funding would need to be secured for national scale-up and may be done through bringing more stakeholders on board and/or the government securing bi-lateral funding for the programme. Due to the SEHP not being included in any public legal policies, there will be limited government support. Seeing this challenge, vertical upscaling plays a significant role to institutionalise the programme so that the MoGE can allocate that budget through the SHNP.

The inclusion of SEHP into the existing SHNP is critical in ensuring sufficient financial resources to support the large-scale expansion. With this vision, the process of institutionalising the programme started in 2016. Resulting from the close collaboration among VAO, MOH and MoGE, a National School Vision Screening Protocol was developed. Besides, the government agencies' involvement in designing and testing the Kafue district's pilot project can help achieve this goal.

During the pilot project, VAO has supported all the expenses, including training and allowances for schoolteachers, consultancy fees for experts, spectacles and medications supply to children, community sensitisation, mobile eye clinics' incurred expenses (fuel, drivers, and vehicle maintenances), and allowances for the public sector eye health team (OCOs, ONs and ophthalmologist) during the activities. The $\mathrm{MOH}$ covered the public sector eye health team's salary.

\section{Element 6 -Determining the role of expansion scaling up (horizontal scaling up)}

According to the 2010 census, there were 4.2 million children aged 7 to 18 years in the country, representing approximately $23 \%$ of Zambia's total population (18 million). Provinces located in the central region have a higher child population when compared to the east and west regions (Copperbelt, Central, and Lusaka), where more than 500,000 children live in each of these provinces. Considering the need and the existing financial and human resources, it will be more realistic to gradually expand the SEHP to a new district rather than a province without compromising the essential components in the programme.

When introducing SEHP to a new site, careful assessment of the local context is crucial to ensure better accommodation and embrace diversity in cultures. Adaptation of SEHP to local needs and settings cannot be neglected as this determines the level of receptivity among the target populations, which can directly influence the programme's impact.[22] There are different demographic characteristics and socioeconomic status within a country, and some may have cultural beliefs that are distinct from other groups of the population. Despite some inevitable adjustments and adaptations of the programme during scaling up, the essential component will remain intact as they are all inter-connected.

\section{Discussion}

This scalability assessment shows that the feasibility of scaling up the comprehensive SEHP is possible if sufficient funding is available. Upscaling should be adapted to the local context to ensure all the programme components are intact. Besides, a few strategies and recommendations made as an output 
of the assessment could facilitate the upscaling process in predicting unwanted shortcomings while improving the programme's effectiveness and efficacy.

One highlight is that the three implementing organisations (VAO, the Zambian $\mathrm{MOH}$ and MoGE) have reached a consensus and shared a common vision - besides expanding the programme to other districts to benefit more children, there will be efforts to advocate for the formalisation of the programme by the government. Having such a shared vision is essential to ensure seamless collaboration and partnership.

Kafue pilot has laid a sound foundation and contributed massively to our knowledge in the future upscaling specified to Zambia's context:

Firstly, the model of the comprehensive SEHP that we have adopted is likely to bring a more significant programme impact. Although a few additional components, such as community sensitisation which may require more time and resources, are essential to gain trust and support from the community. Secondly, it is highly confident that the resource team, which consisted of highly competent and committed individuals across the three implementing organisations, can lead the programme and mobilise the resources during the scaling up. Thirdly, the networking which has already been established during the pilot will facilitate future work.

\section{Conclusion}

Integrating SEHP into the existing SHNP is crucial in ensuring that the programme can be sustained and that more children in the country can access quality eye health services, thus reducing childhood $\mathrm{VI}$ and blindness. Continued efforts such as constant engagement with the government and working closely with strong advocates within the government departments will contribute to the integration's success.

\section{Abbreviations}

\section{DEBS}

District Education Board Secretary; DHO:District Health Officer; IAPB:International Agency for the Prevention of Blindness; MEHC:Mobile Eye Health Clinic; MoGE:Ministry of General Education; $\mathrm{MOH}$ :Ministry of Health; NGO:Non-governmental Organisation; OCO:Ophthalmic Clinical Officer; ON:Ophthalmic Nurse; OT:Optometry Technologist; SDG:Sustainable Development Goal; SHNP:School Health and Nutrition Programme; SEHP:School-based Eye Health Programme; UCVA:Uncorrected Visual Acuity; UK:United Kingdom; UN:United Nations; URE:Uncorrected Refractive Error; UTH:University Teaching Hospital; VA:Visual Acuity; VAO:Vision Aid Overseas; VI:Vision Impairment; WHO:World Health Organisations.

\section{Declarations}

\section{Ethics approval and consent to participate}


This assessment is conducted as part of the school eye health programme evaluation to provide feedback and to inform policy-making. It is a review in nature, and hence it does not require formal ethics approval from the local ethics committee.

\section{Consent for publication}

Not applicable.

\section{Availability of data and materials}

The data collection tool (questionnaires) used and analysed during the current study are available from the corresponding author on reasonable request.

\section{Competing interests}

VFC is a Trustee of VAO; AB is the VAO's Programme Director; IA is the VAO's Deputy Programme Director; GM is the Country Director of VAO Zambia. VAO is an international non-governmental organisation that works to eliminate vision impairment due to uncorrected refractive errors in LMICs.

\section{Funding}

ACY is an independent assessor and received a consultancy fee for the assessment from Vision Aid Overseas (VAO). VAO does not contribute to the study design, data collection and analysis and interpretation of data.

\section{Authors' contributions}

ACY: Conceptualisation, data curation, formal analysis, investigation, methodology, project administration, visualisation, writing - original draft preparation, and writing - review and editing; VFC: Conceptualisation, methodology, visualisation, supervision, writing - original draft preparation, and writing - review and editing; $A B$ : project administration, funding acquisition, supervision, writing - review and editing; GM: project administration, writing - review and editing; IA: project administration, writing review and editing. All authors reviewed and approved the final version of this manuscript. 


\section{Acknowledgements}

We would like to thank the Zambia National Eye Care Coordinator (Professor Muma) and Kafue District Education Planner (Mr Ngalande) for their valuable and crucial inputs during the interviews.

\section{References}

1. Resnikoff S, Pascolini D, Mariotti SP, Pokharel GP. Global magnitude of visual impairment caused by uncorrected refractive errors in 2004. Bull World Health Organ. 2008;86: 63-70.

2. Gilbert C, Bowman R, Malik ANJ, Mafwiri M, Graham R, Hopkins A. Priorities and Challenges (19882018) How far have we come? Comunity Eye Heal J. 2017;30.

3. Glewwe P, Park A, Zhao M. A better vision for development: Eyeglasses and academic performance in rural primary schools in China. J Dev Econ. 2016;122: 170-182. doi:10.1016/j.jdeveco.2016.05.007

4. Glewwe P, Kristine LW, Jongwook L. The Impact of Providing Vision Screening and Free Eyeglasses on Academic Outcomes: Evidence from a Randomised Trial in Title I Elementary Schools in Florida. J Policy Anal Manag PMC. 2018;176: 100-106. doi:10.1016/j.gde.2016.03.011

5. Ma X, Zhou Z, Yi H, Pang X, Shi Y, Chen Q, et al. Effect of providing free glasses on children's educational outcomes in China: Cluster randomised controlled trial. BMJ. 2014;349: 1-12. doi:10.1136/bmj.g5740

6. Ma Y, Congdon N, Shi Y, Hogg R, Medina A, Boswell M, et al. Effect of a local vision care center on eyeglasses use and school performance in rural China a cluster randomised clinical trial. JAMA Ophthalmol. 2018;136: 731-737. doi:10.1001/jamaophthalmol.2018.1329

7. Hannum E, Zhang Y. Poverty and proximate barriers to learning: Vision deficiencies, vision correction and educational outcomes in rural Northwest China. World Dev. 2012;40: 1921-1931. doi:10.1016/j.worlddev.2012.04.029

8. Berle D, Steel Z, Essue BM, Keay L, Jan S, Phuc HT, et al. Multisite prospective investigation of psychological outcomes following cataract surgery in Vietnam. BMJ Glob Heal. 2017;2. doi:10.1136/bmjgh-2016-000162

9. Kumaran SE, Balasubramaniam SM, Kumar DS, Ramani KK. Refractive error and vision-related quality of life in South Indian Children. Optom Vis Sci. 2015;92: 272-278. doi:10.1097/OPX.0000000000000494

10. Chan VF, Singer S, Naidoo KS. Disability-related-distress in primary school learners with vision impairment due to uncorrected refractive error in KwaZulu-Natal Province, South Africa - A qualitative study. PLoS One. 2020;15: 1-16.

11. Republic of Zambia Ministry of Health. Zambia National School-based Eye Health Program. 2020 (unpublished).

12. Gilbert C, Minto H, Morjaria P, Khan I. Standard Guidelines for Comprehensive School Eye Health Programs. 2014. Available: https://www.iapb.org/wp-content/uploads/Standard-Guidelines-forComprehensive-School-Eye-Health-Programs.compressed.pdf 
13. Gilbert C, Bowman R. The Epidemiology of Blindness in Children: Changing Priorities. Community Eye Heal J. 2017.

14. Burnett AM, Yashadhana A, Lee L, Serova N, Naidoo K. Interventions to improve school-based eyecare services in low- and middle-income countries: a systematic review. Bull World Health Organ. 2018;96: 682-694.

15. World Health Organization, ExpandNet. Nine steps for developing a scaling-up strategy. 2010. Available: http://www.who.int/reproductivehealth/publications/strategic_approach/9789241500319/en/

16. Bertram R, Kerns S, Bertram R, Kerns S. Beginning with the end in mind. WHO Libr Cat Data. 2019. doi:10.1007/978-3-030-11325-4_1

17. Republic of Zambia Ministry of Health. Zambia National Health Strategic Plan 2017-2021. 2017. Available: https://www.moh.gov.zm/?wpfb_dl=68

18. Republic of Zambia Ministry of Health. National Eye Health Strategic Plan, Zambia (Year 20172021). 2017.

19. World Health Organization, ExpandNet. Worksheets for Developing a Scaling-up Strategy. 2012. Available: https://expandnet.net/PDFs/MSI-ExpandNet-IBP Case Study 20 case study questions.pdf

20. Muma K, Mumbi W. Eye Health In Zambia. Heal Press Zambia. 2019;03: 2.

21. Chan VF, Omar F, Yard E, Mashayo E, Mulewa D, Drake L, et al. Is an integrated model of school eye health delivery more cost-effective than a vertical model? An implementation research in Zanzibar. BMJ Open Ophthalmol. 2021;6: 1-6. doi:10.1136/bmjophth-2020-000561

22. Fajans P, Simmons R, Ghiron L. Helping public sector health systems innovate: The strategic approach to strengthening reproductive health policies and programs. Am J Public Health. 2006;96: 435-440. doi:10.2105/AJPH.2004.059907 